\title{
Grade 12 students' perceptions on using twitter for vocabulary improvement
}

\author{
Eusebio, Sophya $₫$ \\ Department of Education - Manila, Philippines (Eusebio.sophya@gmail.com) \\ Eusebio, Lea Therese \\ Pamantasan ng Lungsodng Maynila, Philippines (leaeusebio25@gmail.com)
}

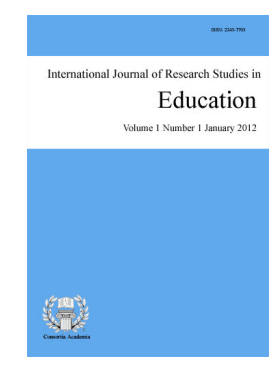

ISSN: 2243-7703 Online ISSN: 2243-7711

Received: 1 September 2020 Available Online: 12 November 2020

\section{Abstract}

This paper explores the grade 12 students' perception on the use of Twitter in improving their vocabulary skills of Grade 12 students. According to the $\mathrm{K}$ to 12 Basic Education Curriculum Senior High School- Core Subject (2013), reading and writing skills' priority is textual and discourse for grade 12 students; which means that it is important for a grade 12 student to acquire a wide range of vocabulary to be able to understand a text and deliver spontaneous speech or presentations. This paper examines the perceptions of grade 12 students on the effectiveness of Twitter as a tool in improving vocabulary skills that are essential for them.

Keywords: vocabulary skills; twitter; vocabulary improvement; twitter features 


\section{Grade 12 students' perceptions on using twitter for vocabulary improvement}

\section{Introduction}

As students are getting promoted level by level, so is their range of learning and information; especially with their vocabulary, and usually, growth in English language vocabulary is always being observed. The 1987 Constitution, Article XIV Section 7, states that "for purposes of communication and instruction, the official languages of the Philippines are Filipino and, until otherwise provided by law, English and the regional languages are the auxiliary official languages in the regions and shall serve as auxiliary media of instruction therein. Spanish and Arabic shall be promoted on a voluntary and optional basis." From this, English has always been given an importance in the Philippines' education and lifestyle.

Vocabulary is a very essential part of learning a language. It is not just reading a new word and knowing its meaning. Walter Petty, Curtis Harold, and Earline Stoll, as cited in Graves (2006) referred to vocabulary as more of "knowledge of words and ability to use the language." Before technology got its advancement, Filipinos have built their English vocabulary with the use of books and motion pictures. Dictionaries are a must. In addition to that, pen pals and written mails and articles are served to practice the use of such language. Nowadays, technological platforms have features for expression of thoughts and, means for acquiring wide range of vocabulary knowledge. Students are now finding other ways how to improve their skills through technological solutions like computers and smart phones. Al-Dawood (2013) stated that students have a choice on the learning strategies they want to use for the improvement of their skills and comprehension. Some note that technology is not solely cut out for education, but with its advancement through time, it has functioned as a teaching tool.

Learning language in Social Network environment is supported by social learning of Vygotsky, which means learning is based on social discourse or interactions (Cole et al., 1978). Siemens (2004), as cited in Kivunja (2014), supported this with Connectivism theory which refers to social networks connecting people and brings up potential reliable sources of knowledge. Thus, aside from what students learn in the classroom, students have to make connections prior to learning to process new knowledge. Clark and Gruba (2010) cited social structures which may be used in language learning despite its limitations. In fact, China has the same SNS as Twitter and that is called Weibo. Weibo works almost the same as twitter, and it also have users that functions differently: social enthusiasts, resenders, readers, opinionated users and inactive users (Chiu et al., 2012, as cited in Harwit, 2014). According to Crystal (2006), as cited in Ranger (2007), though internet as a medium has provided new resources, it still lacks conventional contextual clues such as prosody and gesture, thus concluding that language used on the internet is innovated better, is subversive and is playful. Twitter goes with the same features where Twitter users can read, tweet, reply, favorite or retweet (Madden, 2012, as cited in Greenhow and Gleason, 2012). Madden (2012) supported this furthermore by the conclusion that Twitter has given a productive room for users to socialize interactively or submissively.

\subsection{Background of the study}

In the last few years, the number of researchers and educators are increasing and are beginning to focus on online platforms that motivate students by providing them with wider social networks and authentic tasks (Godwin-Jones, 2008). The adoption of language learning technology, specifically Mobile Assisted Language Learning (MALL), is drawing the attention of many scholars and educators, including those in Saudi Arabia (Nassuora, 2012, as cited Alshalan, 2019).

The online social site twitter, in part responsible for this shifting context, is no longer used solely as an entertainment and advertisement resource. In an academic setting, the framework is also being used to facilitate and promote conversations on specific topics. Lomicka and Lord (2011) referred to Twitter as "an online social 
networking and micro-blogging service that allows its users to read and share very short messages of no more than 140 characters known as 'tweets', shown on the profile page of the author and sent to the 'followers' of the author." Twitter since has become one of the most popular social media tools since the system was designed in San Francisco and first launched in October 2006; currently used by millions of "tweeters," who regularly send and receive messages on the web. It is an effective tool to share information and experiences, to express ideas, to stay in touch with friends, to report on the latest news or to share thoughts and comments on current events, etc. Java et al. (2007) showed people often use Twitter to communicate about their daily activities and share information with like-minded people. Twitter's success can be attributed to the ease with which one can build account information and access information, as well as its availability through a range of mobile devices.

Johnson (2009) commented on Twitter's ability to inspire different audiences to connect, by moving beyond physical boundaries. One aspect of using Twitter in language education that has been the focus of academic debate is the effect of the limitation of characters on sentence production. On the one hand, Castrillo de Larreta-Azelain (2013), as cited in Perez-Sabater (2015), remarked that writing messages of up to 140 characters may be an easier and less intimidating way of starting to write in the target language. The length restriction on messages has also been regarded as Twitter's strength in peer review tasks because students never read long essays from other students in the opinion of Ebner and Maurer (2009), as cited in Perrez-Sabater (2015). Research revealed, on the other hand, that brevity can be a drawback for language learning as students may be reluctant to summarize ideas in such short texts (Ruipérez García, Castrillo de Larreta-Azelain, \& García Cabrero, 2011, cited by Perez-Sabater, 2015). These studies make an undisputed contribution to the field, but further work is still needed to explore Twitter's pedagogical uses, according to Wang and Vásquez (2011). With these being said the researchers took notice and had determined if twitter usage can affect the student vocabulary. The study conducted by Alqunayeer (2016) proved that by using twitter there will be a big chance to improve students' L2 vocabulary since all students has all the access to have twitter due to their generation. According to Santana, García-Santillán, and Pozos-Texon, vocabulary has been one of the most important elements of language learning. Having a wide vocabulary helps language learners understand written and spoken language. It also helps them express their own ideas more completely.

In a study conducted by Al-Dawood (2013), he emphasized the implementation of Twitter conducted to EFL students, which were divided to 2 groups, the control group and experimental group, to know if Twitter would mark improvements in the students' vocabulary The control group has students who studied vocabulary the traditional way and the experimental group has students who studied vocabulary through Twitter. The study has concluded that the experimental group improved a lot than those of the control group, basing on their scores from pre-test and post-test. He also stated that several pedagogical implications for EFL students and teachers can be derived from the study. In particular, the results support the integration of Twitter into a course framework. When using Twitter, students are actively participating and appear to be very motivated to post new tweets. They also cooperated and learned from one another. Some students reported that this was the first time they had used Twitter and they enjoyed the experience. That is why in this study the researchers want to determine if the students have the knowledge whenever they use twitter.

These perceptions that he has recorded from the English as a Foreign Language class has further ignited the curiosity of the researchers to know if it goes the same way with students here in the Philippines. Since 56\% of the Philippines' internet user's population uses Twitter, it is interesting to know if students used Twitter, subconsciously or consciously, effectively in improving their vocabulary.

The researchers want to know the features of twitter that can affect students' improvement of vocabulary skills and its effectiveness. This study aims to help the researchers to gain ideas on twitter being a useful tool in improving one's vocabulary range. In addition, the researchers conducted this study to give a sensible note on the use of social media platform such as twitter and to encourage students who have low vocabulary skills to enhance their knowledge on words and its usage. This study targeted everyone who will benefit from the use of twitter as a tool not limited to expression of thoughts but also the acquisition of vocabulary that will improve 
Eusebio, S., \& Eusebio, L. T.

many aspects in language learning.

\subsection{Statement of the problem}

Main Problem - The study aimed to find out the perceptions of Grade 12 students on the use of Twitter as a tool for improving vocabulary.

Sub-problems - Specifically, the study sought to find the answers to the following:

$>\quad$ What features of Twitter are useful on vocabulary acquisition and understanding?

$>$ How effective is Twitter use on vocabulary skills improvement?

$>\quad$ How much do Grade 12 students know the pronunciation and meaning of Twitters top-tweeted words?

\section{Methods and procedures}

This study used a quantitative research that will investigate an observable phenomenon which is the active usage of twitter of Senior High School Grade 12 students from various Universities. The researchers gathered quantifiable data using Likert-scale survey questionnaire. Utilizing it will able the researchers to determine and interpret the nature of the phenomena and understand the influence Twitter can make in one's vocabulary skills. The researchers used purposive sampling, to which CSUN.edu (p. 22) referred as “... sampling used most often when a difficult-to-reach population needs to be measured". The researchers looked for respondents that are twitter users since between the years 2017-2019, Grade 12 students from different schools under different strands. The researchers chose these respondents because the respondents have taken subjects like Oral Communication, Reading and writing, English for Academic and Professional Purposes, and 21st-century literature which are the subjects for vocabulary development.

The researchers will use a 5-point Likert Scale. Liedke (2020) explained that Likert scales are used to know the attitude of people towards something. Using this 5-point Likert scale, the researchers were able to determine the perceptions of Grade 12 students on the students' vocabulary skills. The researchers used descriptive analysis of the data coming from the survey by identifying the range of the response of the participants in the improvement of their vocabulary using Twitter.

\subsection{Treatment of data}

The data gathered were statistically treated using a Likert scale.

\section{Findings}

The data gathered from the 70 participants who granted us their permission to use their answers in this paper were used to answer the research problems. Twitter has features that promotes both reading and writing for self-expression. It can be used for tweeting one's thoughts or response for another's opinion. It can also be used as a source of information through tweeted text links or article links. In addition, Twitter has its own trending hashtags, topics and highlights that can be about anything- from news to education to ordinary feature storywhich oftentimes present new words used in different context.

The 5-point Likert scale was divided into 3 sections, namely, Twitter Features which related Twitter's usefulness on Vocabulary Acquisition and Understanding, Twitter Use which related on the Effectiveness of Twitter on Vocabulary Skills Improvement, and Twitter Top Vocabulary which relates to Knowledge on Pronunciation and Meaning of Top Tweeted Words. These were used to identify the effectiveness of the use of twitter for improving one's vocabulary skills, from its features, to its improvement benefits, down to the words acquired by grade 12 students who are twitter users.

70 Consortia Academia Publishing (A partner of Network of Professional Researchers and Educators) 
Out of the 70 participants who answered the survey, 15 answered definitely, 24 answered probably, 29 of them said that they possibly have come to know new words through twitter hashtags and trending topics, and 6 replied with probably not. Then for the second item on the survey, 24 of them answered that they have possible learn more words through Twitter's following pages, 14 went for definitely, 20 for probably, 12 for probably not and 2 for definitely not. In addition, 29 grade 12 students possibly discovered vocabulary through twitter's text links, 12 of them said definitely, 25 of them said probably, 10 said probably not and 0 for definitely not. Meanwhile, 34 of them definitely have understood words contextually through twitter threads, while 22 went for probably, 16 for possibly, and 3 for probably not. Lastly, 26 out of 70 grade 12 students chose to answer that they have possibly explored new vocabulary through twitter threads, 22 went for definitely, 18 went for probably, 8 went for possibly not and none for definitely not. According to an interview conducted with the participants, they know the following features of twitter: "tweet, retweet or reply, threads, links, following, hashtags, trending topics and memes." According to them, these features are useful for their vocabulary skills. One participant claims that these features as essential, “....more particularly the 'hashtags'; because it contains all the top issues that I as an individual should know. There are words that being use as way to creatively express their position on the issue." Another participant believes so, because the participant finds unfamiliar words which results to following educational accounts on Twitter. Other asserts that, "these features helps find out topics that i wouldn't normally searched for, so in that case it helps me find new words through these features."

Most of the participants responded that they definitely come to know new words using Twitter, 15 of them answered probably, 22 answered possibly and 5 answered probably not. On the other hand, 27 respondents probably used the words they have known from twitter in their daily conversations, 17 definitely, 21 possibly and 9 of them probably have not used it. Moreover, 30 of them said that they possibly know how to pronounce new words because of twitter and its synonyms, and only 19 of them said definitely, 23 went for probably, and only 1 for probably not. On the other hand, 52 of the participants said that they are definitely aware of the multiple meanings of words used in twitter, 13 said that they are just probably aware of those, 7 said possibly, and 1 answered probably not. When the interviewed participants are asked if they have known new words through Twitter, they unanimously said that it is a "yes" for them. When asked to give examples, they hesitated to give answers. However, they said that they are following informative accounts that are all for meaning and pronunciation and they use it as their reference." When asked if words they have encountered on Twitter were used in their daily conversations or writings such as essays or stories, they said "yes", only if it's "appropriate", or "depending on the topic to discuss."

The researchers gathered 10 words that were trending on Twitter and included it on the survey to know the respondents' familiarity of its meaning and pronunciation. For the word discrimination, 60 respondents answered definitely, 6 for probably, 4 for possibly and none for probably not and definitely not. Second vocabulary word, condemn, is definitely familiar for 40 respondents, while 18 responded probably, 10 possibly, 2 possibly not and none for definitely not. Site has 54 definite familiarity, 10 probably, 6 possibly, and none for possibly not and definitely not. For quarantine, 67 replied with definitely and 3 replied with probably. 'Random' word has 63 'definitely' votes, 6 for probably and 1 possibly. Pledge is definitely known by 55 respondents, 9 for probable, and 6 for possible. The word 'progress' has 65 definite votes and 5 probable votes; while 'influencers' has 60 'definitely' response, 6 for probably and 4 for possibly. Article is definitely known for only 12 respondents, 15 went for probably, 30 for possibly, 7 for probably not and 6 for definitely not. Propaganda received 31 responses for definitely, 10 for probably, 25 for possibly, 2 for each probably not and definitely not.

When the interviewees were asked about these words, its pronunciation and meaning, all of them knew each. They were also asked to use the given words in a sentence or phrase to see if they have a grasp on the meaning and pronunciation of the trending words. One example given for the word discrimination is this sentence from the participant: "She felt discrimination because of the color of her skin." For the word condemn, one participant used it in a political way in this sentence: "People condemn what is wrong with the ones running our government.' Site was used as a subject in this sentence from one of the interviewees: "The site was hacked." The word 'quarantine' is used as an object in this sentence: "We can't go outside due to quarantine.' One 
Eusebio, S., \& Eusebio, L. T.

participant used random in this phrase with a smart contextual clue: "a random sequence of letters". Meanwhile, pledge used in a sentence by a participant showed up like this: "Everyday, we pledge allegiance to the flag." On the other hand, influencer is used in a sentence as: "If you are a good influencer, you must influence others to have good attitude." A participant used 'progress' as something related to COVID-19: "There was no progress regarding the Philippine Government in fighting COVID." In this sentence, a participant clearly contextualizes the use of article: "An article states that COVID will not end for the next few years." Another clearly contextualized meaning of a trending word on twitter, propaganda, is set in a sentence like this by one of the interviewees: "The report was nothing but lies and propaganda."

\subsection{Profile of the respondents}

The profile of the respondents sought for this study is in terms of their grade level.

\section{Table 1}

Respondents' grade level and population

\begin{tabular}{cccc}
\hline Grade Level & Male & Female & Total \\
\hline 12 & 33 & 37 & 70 \\
\hline
\end{tabular}

The students were randomly chosen and asked permission to answer the survey. There were 33 male, grade 12 students and 37 female grade 12 students who willingly took the survey.

\subsection{Responses to the survey}

There were 3 key findings: Twitter's features appeared to be effective enough for students to use to help improve their vocabulary skills; Vocabulary skills learned through twitter marks an effective one for vocabulary improvement, and Twitter was helpful in learning words' meaning and pronunciation.

\section{Table 2}

Twitter features

\begin{tabular}{|c|c|c|c|c|c|}
\hline Usefulness on vocabulary acquisition and understanding & $D$ & $\operatorname{Pr}$ & $\mathrm{P}$ & PN & DN \\
\hline I learn new words through Twitter's hashtags and trending topics. & 15 & 24 & 29 & 6 & 0 \\
\hline I come to know more English words through twitter following. & 14 & 20 & 24 & 12 & 2 \\
\hline I discover vocabulary through tweeter's text links. & 12 & 25 & 29 & 10 & 0 \\
\hline I understand words contextually though twitter threads. & 34 & 22 & 16 & 3 & 0 \\
\hline I explore new vocabulary through tweets/retweets and replies. & 22 & 18 & 26 & 8 & 0 \\
\hline
\end{tabular}

On Twitter's Vocabulary Acquisition Feature, it was observed that majority of the respondents answered 'possibly', with 1.77 mean (average response to the survey).

\section{Table 3}

Twitter use

\begin{tabular}{|c|c|c|c|c|c|}
\hline Effectiveness on vocabulary skills improvement & $D$ & $\operatorname{Pr}$ & $\mathrm{P}$ & $\mathrm{PN}$ & $\mathrm{DN}$ \\
\hline $\begin{array}{l}\text { I come to know new words using Twitter. It would be easier than } \\
\text { commuting to get to my school }\end{array}$ & 33 & 15 & 22 & 8 & 0 \\
\hline $\begin{array}{l}\text { I use the words I have known through Twitter in my daily conversations. I } \\
\text { can have a sense of responsibility for learning my foreign language }\end{array}$ & 17 & 27 & 21 & 9 & 0 \\
\hline I know how to pronounce new words because of twitter. & 19 & 15 & 30 & 10 & 1 \\
\hline I know the synonyms of the words I discovered in twitter. & 19 & 23 & 30 & 1 & 0 \\
\hline I am aware that words used in twitter have multiple meanings. & 1 & 2 & 3 & 4 & 5 \\
\hline
\end{tabular}

Meanwhile, the highest mean (average response) for Vocabulary Skills Improvement Using Twitter was 2; that is for definitely scale. Mostly, the respondents consistently answered definitely and second to that was the answer, possibly. 
Table 4

Twitter top vocabulary

\begin{tabular}{|c|c|c|c|c|c|}
\hline Knowledge on pronunciation and meaning of top tweeted words & $D$ & $\operatorname{Pr}$ & $\mathrm{P}$ & PN & $\mathrm{DN}$ \\
\hline Discrimination & 64 & 6 & 4 & 0 & 0 \\
\hline Condemn & 40 & 18 & 10 & 2 & 0 \\
\hline Site & 54 & 10 & 6 & 4 & 0 \\
\hline Quarantine & 67 & 3 & 0 & 0 & 0 \\
\hline Random & 63 & 6 & 1 & 0 & 0 \\
\hline Pledge & 55 & 9 & 6 & 0 & 0 \\
\hline Progress & 65 & 5 & 0 & 0 & 0 \\
\hline Influencers & 60 & 6 & 4 & 0 & 0 \\
\hline Article & 12 & 15 & 30 & 7 & 6 \\
\hline Propaganda & 31 & 10 & 25 & 2 & 2 \\
\hline
\end{tabular}

On the other hand, when it comes to the vocabulary words known through twitter regarding its meaning and pronunciation, a 7.24 mean (average response) were gotten from the answers of the respondents.

\section{Conclusion}

Using Twitter is generally considered as informal learning. However, Twitter, if used contextually and implicitly, can be used more than just a social media site. It can be of educational use if it will be used with plans and goals to circle around its limitations, especially with students' exposure to various topics which may be inappropriate or needs proper guidance. Twitter's features are as flexible as its daily function when used in teaching-learning process, if using it will be accompanied by comprehensive and direct instructions, and meaningful and implicit communication. Twitter can address learning for the four, main macro skills in learning English, and learning those means acquiring vocabulary of the language meaningfully. Mostly, words in Twitter are the ones which are commonly used. However, since pressing issues of today, political, economic or in academe run around the social media site, students of different ages and grade level get to acquire new words which improve their vocabulary.

Twitter's discussion feature through tweets, retweets, replies, threads and links are helpful for understanding further the newly met words. In addition, pronunciation of these words can be accessed by videos or twitter pages to follow which provides vocabulary lesson in a microblog form. Meaning of words are searchable, since trending topics and hashtags stay for long to be accessed by users who wanted to catch up or who wanted to know more. Features like these are very comprehensive for a microblogging site, thinking through the access despite the limitations on tweets. Using these features with specific instructions under specific goals would be beneficial to effectively acquiring and learning vocabulary. Though characters for tweeting is limited, Twitter can be flexible enough to cater the four macros kills where vocabulary from a second language is usually used, namely, listening, speaking, reading and writing. Since vocabulary skills improvement is essential for comprehension, all four of these macro skills would benefit from it. Tweeted videos can benefit listening comprehension and speaking skills, while tweets, replies, retweets, hashtags, trending topics, threads, link to articles, can be beneficial to reading and writing. Basically, twitter is of help when utilized properly and comprehensively. Understanding further its features, its own world of literacy has a big chance to be a constant part of language education, especially now that educational system has to go beyond integrating ICT.

\subsection{Recommendations}

The following recommendations are hereby given based on the findings and conclusions of this study.

For the Department of Education, educators and the school administrators- Integrating technology should not only be introduced and integrated shortly in the class, but also be included in every possible lesson or output in a lecture to make things in class more interesting and within the exposure of the students. Technology can be a huge part of mastery in any subject if used contextually. 
Eusebio, S., \& Eusebio, L. T.

For the community stakeholders- Teachers and students should be encouraged to use technology, may it be over the internet or not, to be used as a helpful tool in learning.

For the parents- Social media may be too much to handle and control between parents and kids, but despite its cons, it can be used for learning if the school and parents will provide guidance. It is important that aside from support and encouragement, understanding and motivation is present.

For the future researchers- Researchers should be encouraged to boldly explore and analyze different helpful features of various social networking sites to be more grounded in the modern education.

\section{References}

Al-Dawood, M. M. N. (2013). Tweet, share and learn; the effect of micro-blogging on Twitter on the vocabulary improvement of Saudi female EFL college students. https://files.eric.ed.gov/fulltext/ED573932.pdf

Alqunayeer, H. S. (2016). The impact of teaching through twitter on students' vocabulary learning: A case study of Qassim University. World Journal of English Language, 6(2), 35-43. https://doi.org/10.5430/wjel.v6n2p35

Alshalan, K. (2019). Investigating EFL Saudi students' vocabulary improvement in micro-blogging on twitter at Imam University. International Journal of Linguistics, Literature and Translation, 2(2), 108-115. https://doi.org/10.32996/ijllt.2019.2.2.18

Clark, C., \& Gruba, P. (2010). The use of social networking sites for foreign language learning: An autoethnographic study of Livemocha. In the Proceedings of ascilite Sydney 2010 (pp. 164-173). Australia.

Cole, M., John-Steiner, V., Scribner, S., \& Souberman, E.(Eds.) (1978). L. S. Vygotsky, Mind in society: The development of higher psychological processes. Harvard University Press.

Csun.edu. (2007). Chapter 8: Quantitative sampling. http://www.csun.edu/ hbsoc126/soc4/chapter_8_outline.pdf

Godwin-Jones, R. (2018). Second language writing online: An update. Language Learning \& Technology, 22(1), 1.

Graves, M. F. (2006). The vocabulary book: Learning and instruction. Teachers College Press.

Greenhow, C., \& Gleason, B. (2012). Twitteracy: Tweeting as a new literacy practice. The Educational Forum, 76(4), 464-478. https://doi.org/10.1080/00131725.2012.709032

Harwit, E. (2014). The rise and influence of Weibo (Microblogs) in China. Asian Survey, 54(6), 1059-1087. https://doi.org/10.1525/as.2014.54.6.1059

Java, A., Song, X., Finin, T., \& Tseng, B. (2007). Why we twitter. In the Proceedings of the 9th WebKDD and 1st SNA-KDD 2007 Workshop on Web Mining and Social Network Analysis. https://doi.org/10.1145/1348549.1348556

Johnson, S. (2009). Back to article click to print how Twitter will change the way we live. http://individual.utoronto.ca/kreemy/proposal/04.pdf

Kivunja, C. (2014). Do you want your students to be job-ready with 21st century skills? Change pedagogies: A Pedagogical paradigm shift from Vygotskyian social constructivism to critical thinking, problem solving and Siemens' digital connectivism. International Journal of Higher Education, 3(3), 81-91. https://doi.org/10.5430/ijhe.v3n3p81

Liedke, L. (2019, April 24). Beginner's guide: What is a Likert scale and how to use it? WPForms. https://wpforms.com/beginners-guide-what-is-a-likert-scale-and-how-to-use-it/

Lomicka, L., \& Lord, G. (2012). A tale of tweets: Analyzing microblogging among language learners. System, 40(1), 48-63. https://doi.org/10.1016/j.system.2011.11.001

Pérez-Sabater, C. (2015). ESP vocabulary and social networking: The case of Twitter. Www.Academia.Edu. https://www.academia.edu/12071865/ESP_vocabulary_and_social_networking_The_case_of_Twitter

Ranger, G. (2007). David Crystal: Language and the internet. Cambridge University Press. https://doi.org/10.4000/lexis.1831

74 Consortia Academia Publishing (A partner of Network of Professional Researchers and Educators) 
Grade 12 students' perceptions on using twitter for vocabulary improvement

Santana, J., García-Santillán, A., \& Pozos-Texon, F. (2014). Learning vocabulary through Twitter. ICERI2014 Proceedings, 4178-4184. https://library.iated.org/view/SANTANA2014LEA 
Eusebio, S., \& Eusebio, L. T.

76 Consortia Academia Publishing (A partner of Network of Professional Researchers and Educators) 